\title{
Primary Mucinous Adenocarcinoma of Gall Bladder: A Rare Case Report
}

\author{
Mahendra Singh $^{1}$, Anveksha Sachan ${ }^{2 *}$, Anita Omhare ${ }^{3}$, Neelima Verma ${ }^{4}$, Swetlana Sachan ${ }^{5}$ \\ ${ }^{1}$ Professor and Head, Department of Pathology, GSVM Medical College Kanpur, India \\ ${ }^{2}$ Junior Resident, Department of Pathology, GSVM Medical College Kanpur, India \\ ${ }^{3}$ Lecturer, Department of Pathology, GSVM Medical College Kanpur, India \\ ${ }^{4}$ Associate Professor, Department of Pathology, GSVM Medical College Kanpur, India \\ ${ }^{5}$ Junior Resident, Department of Pathology, GSVM Medical College Kanpur, India
}

*Address for Correspondence: Dr. Anveksha Sachan, Junior Resident, Department of Pathology, GSVM Medical College, Kanpur, Uttar Pradesh, India

E-mail: riyasachan12@gmail.com

Received: 21 Aug 2018/ Revised: 27 Oct 2018/ Accepted: 23 Dec 2018

\begin{abstract}
Background: Mucinous carcinoma of gall bladder is a rare variant of gall bladder carcinoma. Mucinous carcinoma of gall bladder is characterized by extracellular mucin comprising of $>50 \%$ of tumor volume.

Methods: We reported a case of 50 years old female with chief complaints of pain in right hypochondriac region, vomiting, weight loss, loss of appetite and indigestion. Her liver function test was deranged. Ultrasonography revealed markedly distended gall bladder with thickened and edematous wall and lumen was filled with multiple calculi. Contrast enhanced Computed Tomography (CECT) revealed multiple enlarged lymph nodes. Carbohydrate antigen (CA) 19.9 cancer marker was found within normal limit. Diagnosis was confirmed by histopathological examination of cholecystectomy specimen.

Results: Patient presents with pain in right hypochondriac region, weight loss, loss of appetite and on histopathological examination of gall bladder, findings are suggestive of primary mucinous adenocarcinoma of gall bladder.

Conclusion: Mucinous adenocarcinoma was a rare variant of gall bladder carcinoma. It has more aggressive behavior and worse prognosis than that of conventional adenocarcinoma of Gall Bladder
\end{abstract}

Key-words: Cholecystectomy, Gall bladder, Hypochondriac, Mucinous adenocarcinoma, Mucin

\section{INTRODUCTION}

Mucinous Carcinoma of gall bladder is a rare variant of gall bladder carcinoma, constitutes $2.5 \%$ of gallbladder carcinomas. Mucinous carcinoma of gallbladder is characterized by extracellular mucin comprising $>50 \%$ of tumor volume ${ }^{[1]}$. When mucinous component exceeds $90 \%$ of the tumour is labeled as pure mucinous carcinoma ${ }^{[2-4]}$. We reported a case of mucinous adenocarcinoma of gallbladder. Mucinous cell carcinoma is a very uncommon neoplasm of gallbladder, most of them displaying a mixed-mucinous histological picture.

\section{How to cite this article}

Singh M, Sachan A, Omhare A, Verma N, Sachan S Primary Mucinous Adenocarcinoma of Gall Bladder: A Rare Case Report. SSR Inst. Int. J. Life. Sci., 2019; 5(1): 2196-2200.

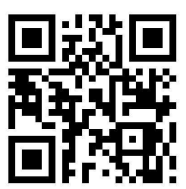

Access this article online www.ijlssr.com
Most carcinomas arise in the fund us (60\%), body (30\%) and neck $(10 \%){ }^{[5]}$. Tumor has a poor prognosis because of its tendency toward invasive growth ${ }^{[5]}$. Approximately 3:1 ratio between female: male occur and most patients are older than 50 years ${ }^{[6]}$. Carcinomas with copious mucin production are now thought to form distinct category among malignancies of gall bladder ${ }^{[6]}$. It's incidence increases with age ${ }^{[6]}$. Risk factor for gall bladder carcinoma is well known but a definite epidemiologic parallel between gall bladder carcinoma and cholelithiasis occur ${ }^{[6]}$.

\section{MATERIALS AND METHODS}

Cholecystectomy specimen and the hysterectomy specimen of the same patient were sent for histopathological examination in our Department of Pathology, GSVM Medical College, Kanpur, India from a private hospital in the year of 2018. Both the specimens 
were fixed in $10 \%$ buffered formalin for 24-48 hours. After that the tissues were processed and stained by hematoxylin and eosin staining and then mounted with DPX.

\section{CASE REPORT}

A 50 years old female was presented with complaints of pain in the right hypochondriac region, vomiting, and weight loss since 45 days along with the history of loss of appetite and indigestion for 20 days.

On examination, her vital parameters were within normal limits. Renal function test was within the normal limit. Hematological parameters revealed mildly raised. TLC was found the 13,300 cells $/ \mathrm{mm}^{3}$. Biochemical investigation (liver function test) was shows deranged parameters in Table 1.

\section{Table 1: Liver function test}

\begin{tabular}{ccc}
\hline $\begin{array}{c}\text { Biochemical } \\
\text { parameters }\end{array}$ & $\begin{array}{c}\text { Obtained } \\
\text { value }\end{array}$ & $\begin{array}{c}\text { Normal reference } \\
\text { Range }\end{array}$ \\
\hline $\begin{array}{c}\text { S. Bilirubin Total } \\
\text { Direct }\end{array}$ & $\begin{array}{c}13.1 \mathrm{mg} / \mathrm{dl} \\
2.0 \mathrm{mg} / \mathrm{dl}\end{array}$ & $0.3-1.0 \mathrm{mg} / \mathrm{dl}$ \\
Indirect & $11.1 \mathrm{mg} / \mathrm{dl}$ & $0.4 \mathrm{mg} / \mathrm{dl}$ \\
S.G.P.T. & $108 \mathrm{U} / \mathrm{L}$ & $5-42 \mathrm{Ug} / \mathrm{L}$ \\
S.G.O.T. & $130 \mathrm{U} / \mathrm{L}$ & $5-40 \mathrm{U} / \mathrm{L}$ \\
S. Alkaline & $1485 \mathrm{U} / \mathrm{L}$ & $25-120 \mathrm{U} / \mathrm{L}$ \\
phosphatase & & \\
\hline
\end{tabular}

USG findings of the patient revealed markedly distended gall bladder with thickened and edematous gallbladder wall and lumen was filled with multiple calculi. The proximal part of common bile duct not adequately visualized due to theedematous gallbladder wall. A Liver was mildly enlarged with intra-hepatic biliary channels slightly dilated. One month after cholecystectomy, CECT whole abdomen was performed which revealed multiple lymph nodes in peri-portal, peri-pancreatic, coeliac, pre-aortic, para-aortic, aorto-caval lymph nodes up to $1.5 \mathrm{~cm}$ - Lymph nodal secondaries. Also, there were mild as cites with mild hepatosplenomegaly.

* CA 19.9 cancer marker was also done, which was found within normal limit.
Gross- Cholecystectomy and hysterectomy specimen of the same patient were sent to pathology department of GSVM Medical College, Kanpur, in two separate jars for histopathological examination.

JAR I was labeled gall bladder as, Cholecystectomy specimen measured $8 \times 4$ and $5 \times 2 \mathrm{~cm}$. The outer surface showed few fibro fatty adhesions. On cut section inner surface showed glistening mucosa with a greyish white area. Wall thickness varies from 1.5 to $2 \mathrm{~cm}$. There were multiple stones inside the jar shown in Fig. $1(A, B)$.

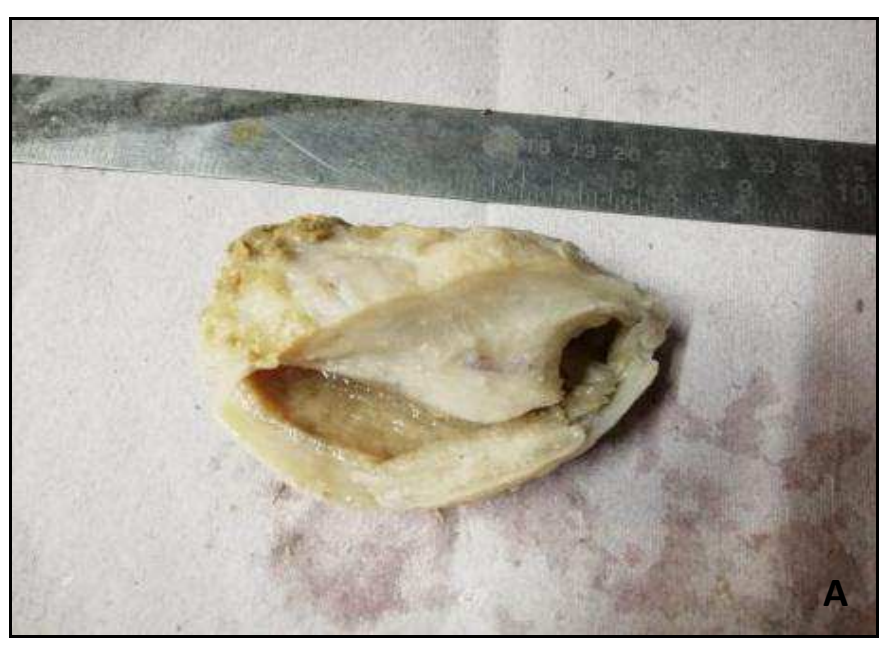

Fig. 1 (A): Cholecystectomy specimen shows a greyish white area

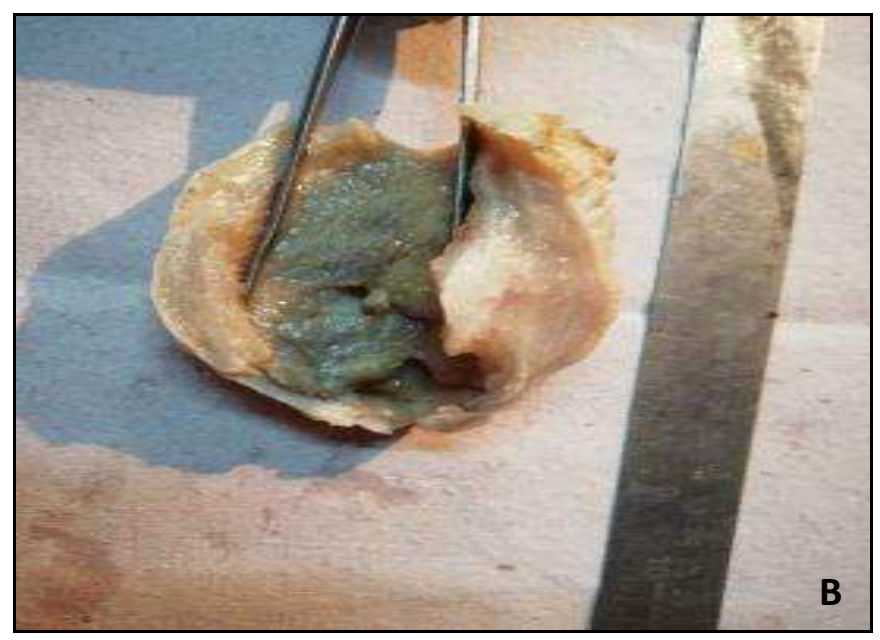

Fig. 1 (B): Cholecystectomy specimen shows a glistening mucosa on cut section

JAR II was labeled total abdominal hysterectomy. The specimen consisted of the uterus, cervix with bilateral adnexa.

Microscopy examination- Multiple H \& E stained sections from gall bladder were examined showing marked thickening of gallbladder wall comprising of mucosa, muscular layer and serosa. 
Numerous well demarcated mucin pools with atypical cells (floating into the mucin pools) having a high nucleocytoplasmic ratio, moderate amount of vacuolated cytoplasm, were seen on the mucosal surface (Fig. 2 to Fig. 5).

These mucin pools were surrounded by inflammatory cells infiltrate comprising of mature lymphocytes,

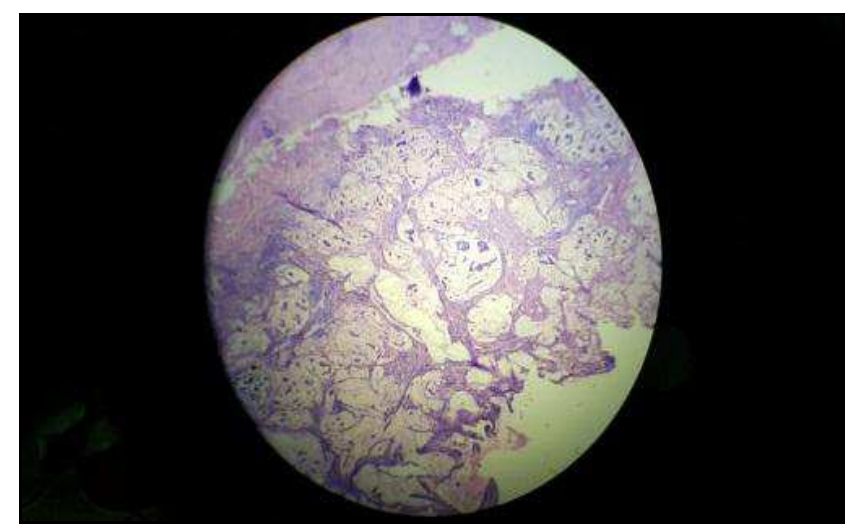

Fig. 2: Scanner view (4x) shows well-demarcated mucin pools

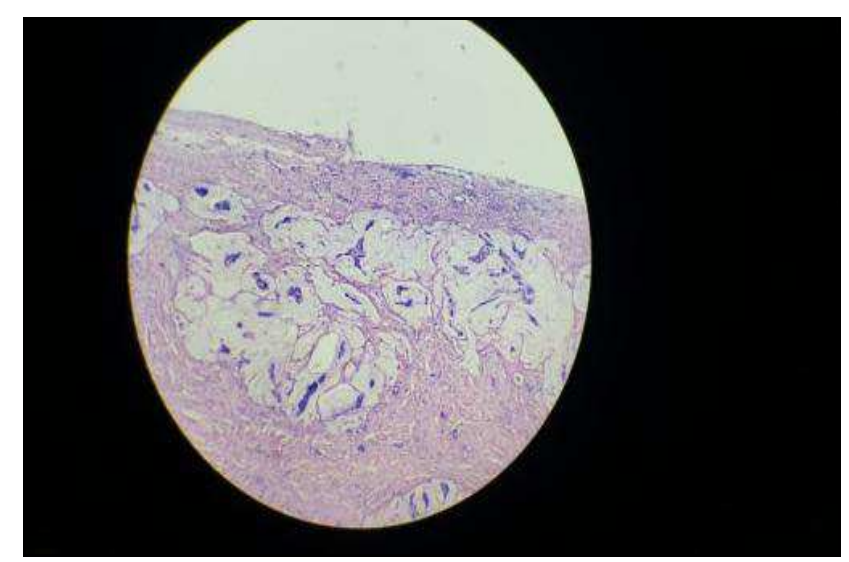

Fig. 4: Low power view (10x) shows an involvement of serosa

\section{DISCUSSION}

Gallbladder carcinoma is the fifth most common G. I. malignancy ${ }^{[7]}$. It is a disease of elderly, more common in females than in males (3:1) and there are various types of gall bladder carcinoma such as adenocarcinoma, squamous cell carcinoma, adenosquamous carcinoma and very rare mucinous adenocarcinoma ${ }^{[5]}$.

Mucinous carcinoma has two histologic variants. One with large pool of extracellular mucin with groups of tumour cells and other type with cystically dilated mucin filled glands. These may be present either alone or in combination $^{[1]}$. macrophages and fibroblasts along with few congested and dilated blood vessels. These atypical cells and mucin pools were also in filtrating the muscle layer with similar picture and were also involving upto the serosa. Findings were suggestive of primary mucinous adenocarcinoma of gallbladder. Microscopic findings of received hysterectomy specimen were histopathologically normal.

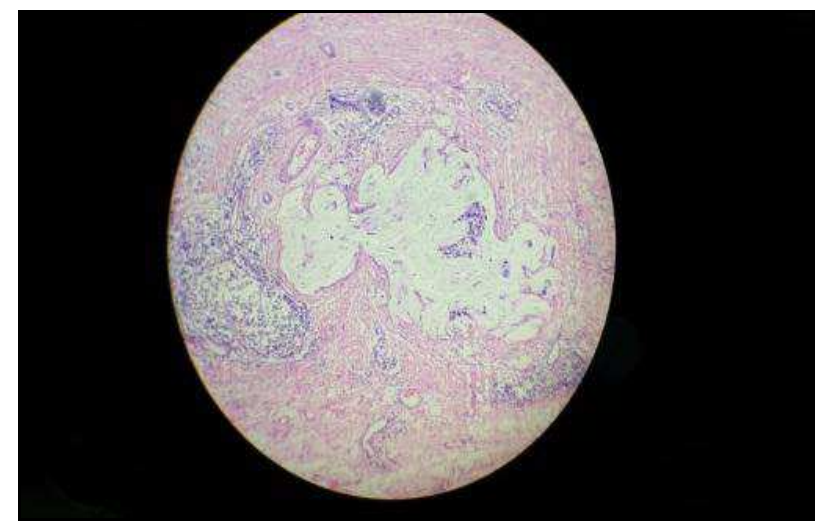

Fig. 3: Low power view (10x) shows mucin pool surrounded by inflammatory cells infiltrate and few blood vessels

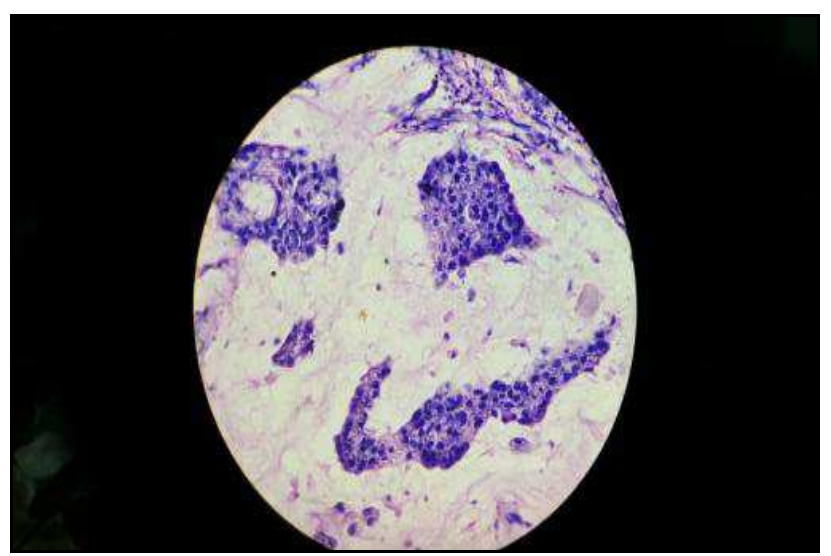

Fig. 5: High power view (40x) shows clusters of neoplastic cells floating in mucin

In the majority of cases mucinous adenocarcinoma was frequently well differentiated and admixed with conventional adenocarcinoma but poorly differentiated mucinous adenocarcinoma with distant metastasis can be found. Focal mucinous differentiation and well differentiated adenocarcinoma with intra glandular mucin also occur ${ }^{[8]}$. Mucinous carcinoma constitutes only $2.5 \%$. This was rather uncommon in gall bladder and is noted in the literature mostly as individual case reports or small handful of cases ${ }^{[6]}$.

Presence of gall stones is one of the major risk factors for gallbladder adenocarcinoma, as in our case report but 
$10-25 \%$ of patients with gall bladder carcinoma. They do not have associated cholelithiasis ${ }^{[9]}$. We can differentiate mucinous carcinoma from conventional gall bladder adenocarcinoma by MUC 2 positivity and from intestinal carcinoma by an inverse CK7/CK20 profiles ${ }^{[10]}$ CK7 (+) and CK20 (-) $)^{[11]}$.

It was CDX2 (Negative) so can be differentiated from pancreatic mucinous carcinoma ${ }^{[12]}$. It was MUC6 (Negative) so can be differentiated from mammary colloid carcinoma ${ }^{[13]}$. Owing to the location of gallbladder, dissemination of tumor to adjacent tissue is usually present at the time of diagnosis. Most patients were not suitable for curative surgery because of advanced stage of the disease ${ }^{[7]}$.

\section{CONCLUSIONS}

Mucinous adenocarcinoma is a rare variant of gall bladder carcinoma. It has more aggressive behavior and worse prognosis than that of conventional adenocarcinoma of gall bladder. Most mucinous carcinoma is a mixed-mucinous, not pure colloid type. It is very essential to differentiate a primary mucinous adenocarcinoma from metastatic mucinous adenocarcinoma arising from other sites/organs because of different modes of treatment and different prognosis. Tumour markers have the increasing significance in the diagnosis and evaluation of gall bladder carcinoma. Assay of carbohydrate antigen (CA) 242, carbohydrate antigen (CA) 15-3, carbohydrate antigen (CA) 19-9 and carbohydrate antigen (CA) 125 are fairly good markers for discriminating patients of carcinoma of the gall bladder from cholelithiasis. CA242 and CA125 when used together achieved best sensitivity and specificity. Serum markers seem to be less sensitive when used individually in carcinoma of the gall bladder but may prove useful in combination.

\section{ACKNOWLEDGMENTS}

The authors are highly grateful to the respective Universities and Principals of relevant Institutions to carry out the present investigations.

\section{CONTRIBUTION OF AUTHORS}

Research concept- Dr. Anveksha Sachan

Research design- Dr. Neelima Verma

Supervision- Dr. Anita Omhare

Materials- Dr. Anita Omhare

Data collection- Dr. Anita Omhare
Data analysis and interpretation- Dr. Anita Omhare

Literature search- Dr. Swetlana Sachan

Writing article- Dr. Anveksha Sachan

Critical review- Dr. Mahendra Singh

Article editing- Dr. Anveksha Sachan

Final approval- Dr. Anveksha Sachan

\section{REFERENCES}

[1] Albores-Saavedra J, Menck HR, Scoazec JC, Soehendra N, Wittekind C, Sriram PV, et al. Carcinoma of the gallbladder and extra hepatic bile ducts. In: Hamilton SR, Aaltonen LA, editors. WHO Classification of Tumors. Pathology and Genetics of Tumors of the Digestive system. Lyon: IARC Press, 2000; pp. 206-12.

[2] Adsay VN, Klimstra DS. Benign and malignant Tumors of gall bladder and extra hepatic biliary tract. In: Odze RD, Goldblum JR, editors. Surgical pathology of the GI tract, liver, biliary tract and pancreas. $2^{\text {nd }}$ ed. Philadelphia: Saunders Elsevier 2009; pp. 857-70.

[3] Adsay VN. Gall Bladder, Extra hepatic biliary Tree, and Ampulla. In: Mills SE, editor. Sternberg's Diagnostic surgical pathology. $5^{\text {th }}$ ed. Lippincott Williams and Wilkins. 2010; pp. 1620-24.

[4] [1] Gupte PA, Chaturvedi R, Patil LY, Joshi AS. Pure mucinous (Colloid) adenocarcinoma of the Gall bladder- A rare phenotype. Oncol. Gastroenterol. Hepatol. Reports, 2013; 2(1): 27-29.

[5] Misra S, Chaturvedi A, Misra NC, Sharma ID. Carcinoma of gall bladder. Lancet oncol., 2003; 4(3): 167-76.

[6] Tangde AR, Rathod SG, Joshi AR, Bindu RS. Mucinous adenocarcinoma of gall bladder: A case report. Int. J. Res. Med. Sci., 2017; 5(11): 5082-84.

[7] Abd-Allah MA, Ali MHM, O. Khalid I, Gazali M, Dr M. Allata AA. Mucinous Adenocarcinoma of the Gallbladder: A Case Report. Int. J. Multidisciplinary and Current research, 2016; 4: 37-38.

[8] Singh M, Vishwakarma I, Purwar N, Verma YN, Sharma T. Mucinous carcinoma of Gall Bladder an incidental Finding of a rare case. Int. J. Life Sci. Scient. Res; 2017; 3(5): 1411-14.

[9] Dursun N, Escalona OT, Roa JC, Basturk O, Bagci P, et al. Mucinous carcinoma of Gall bladder: Clinicopathologic analysis of 15 cases identified in 606 carcinomas. Arch. Pathol. Lab. Med., 2012; 136(1): 1347-58. 
[10]Allah AAM, Ali MHM, et al. Mucinous Adeno carcinoma of gall bladder: A case report. Int. J. of multidisciplinary and current research, 2016; 4: 37-38.

[11]Mills SE, Greenson JK, et al. Surgical histopathology Sternberg's $6^{\text {th }}$ edition; $2015 ; 1797-1802$.
[12]Miller SE, Greenson JK, et al. Surgical histopathology Sternberg's 6 ${ }^{\text {th }}$ Ed: 2015, pp. 1617.

[13]Rosai J. Ackerman's surgical pathology Rosai \& Ackerman's. $10^{\text {th }}$ Ed: 2012, pp. 1700. 